\title{
Evidence based library and information practice (EBLIP) i Sverige
}

\author{
Af Lotta Haglund
}

\begin{abstract}
Artiklen tager afscet $i$ en definition af evidence-based library and information practice (EBLIP), der laegger vagt på en bred definition omfattende både brugerrapporteret, bibliotekar observeret og forskningsbaseret evidens. Her slås også fast, at svenske biblioteker er relativt stcerke på de to første felter: den brugerrapporterede og den bibliotekar observerede evidens og sammenlignet hermed svagere med hensyn til den forskningsbaserede evidens. Artiklen kortlagger herefter en rakke kritikpunkter og barrierer med scerlig relevans for Sverige i forhold til brugen af forskningsbaseret evidens såsom evidensbevagelsens toette tilknytning til naturvidenskabeligt progede forskningstraditioner, en udbredt oplevelse af konceptet som dogmatisk og sartrcek ved bibliotekaruddannelsen og organisationskulturen i mange biblioteker. I artiklen henvises til en rakke EBLIPinspirerede initiativer og aktiviteter $i$ Sverige: effekten på bibliotekaruddannelsernes indhold, den svenske biblioteksforenings indsatser og publikationer, svenske bibliotekarers engagement og indsats $i$ forhold til de tilbagevendende, internationale EBLIP konferencer og $i$ scerdeleshed Karolinska Institutets Universitetsbiblioteks (KIB) centrale rolle som primus motor i forhold til kompetenceudvikling, kurser, konferencer og workshops fremhaves. Optimistisk
\end{abstract}

Lotta Haglund er ansat som Informationschef ved Karolinska Institutets Universitetsbibliotek i Stockholm.Lotta.Haglund@ki.se vurderes det, at aktiviteterne har betydet, at det dokumenterede yderst beskedne kendskab til EBLIP blandt svenske bibliotekarer i 2007 nu sandsynligvis er blevet forbedret.

Det finns inget vedertaget begrepp på svenska för evidence based library and information practice, men flera olika sätt att uttrycka konceptet förekommer, exempelvis evidensbaserat biblioteksarbete, teoretiskt underbyggd bibliotekspraktik eller reflekterande praxis, och begreppet länkas ofta till forskningsanvändning i praktiken (Se t ex Thorell, 2010 och Pilerot, 2007). I den fortsatta texten kommer förkortningen EBLIP att användas.

Enligt en av definitionerna av EBLIP-konceptet är EBLIP:

“... ett arbetssätt inom biblioteks- och informationsverksamhet som förordar insamling, tolkning och integration av giltiga, viktiga och tillämpbara användarrapporterade, av bibliotekarier observerade och forskningsbaserade evidens. Bästa tillgängliga evidens, anpassade efter användarnas behov och preferenser, används för att öka kvaliteten hos professionella bedömningar ..." (Egen översättning - LH). (Booth \& Brice, 2004)

Många bibliotekarier i Sverige skulle förmodligen säga att vi är ganska bra på användarrapporterade och av bibliotekarier observerade evidens, men svagare på den forskningsbaserade delen. När man diskuterar EBLIP som arbetssätt tenderar därför fokus 
att hamna på just forskningsanvändningen. Ett annat bekymmer är den relativt svaga kunskapsbasen ur ett svenskt/nordiskt perspektiv, då det, trots många likheter, ändå kan vara svårt att använda sig av vetenskaplig litteratur från den anglosaxiska världen, eftersom det finns relativt stora organisatoriska, men även kulturella skillnader.

Det vore önskvärt att fler skriver om sina projekt och utvecklingsarbeten, och att det också fanns ett nationellt repositorium eller liknande för biblioteksrelaterad FoU. I ett skede då Kungliga Biblioteket har fătt utökat ansvar för samordning av bibliotek inom alla bibliotekstyper kanske det finns ökade möjlighet till detta.

\section{Kritik mot EBLIP}

I Sverige finns en viss skepsis mot begreppet evidens, av minst tre anledningar. På ett ytligt plan reagerar många på att det upplevs som dålig svenska ("svengelska"), samtidigt som det kopplas tätt samman med medicin, och därmed klassas som något enbart intressant för medicinska bibliotek. Sist men inte minst ifrågasätts om man egentligen kan tala om evidens/bevis. Bevis återknyter till naturvetenskapen (=medicin) och för tankarna till något helt igenom rationellt underbyggt, svart eller vitt, vilket kan upplevas som svårt att införliva i vårt kvalitativt orienterade biblioteks- och informationsvetenskap (Pilerot 2007, samt personlig kommunikation november 2010).

Ett annat tungt vägande argument mot EBLIP som arbetssätt är upplevelsen av att det är ett förhållandevis dogmatiskt arbetssätt, som man antingen genomför fullt ut eller inte alls, och med tydliga hierarkier för de funna bevisen. Även detta argument kan hänföras till eventuell kunskap om evidensbaserad medicin. Det kanske tyngst vägande skälet mot EBLIP som arbetssätt är att det upplevs som oerhört tidsödande, och därmed omöjligt att implementera i den dagliga verksamheten.

\section{Hinder för EBLIP}

En majoritet av de yrkesverksamma bibliotekarierna i Sverige, och många av de som innehar ledande befattningar på biblioteken, utbildade sig till bibliotekarier i en tid då utbildningen var en utpräglad yrkesutbildning. Detta i kombination med att kulturen på många arbetsplatser inte inbegriper att man håller sig à jour med den vetenskapliga litteraturen inom biblioteks- och informationsvetenskap gör att det finns en svag tradition när det gäller att använda sig av vetenskapliga rön för att utveckla verksamheten. Det betyder naturligtvis inte att det inte görs, men i något begränsad omfattning.

Ett annat hinder för användningen av vetenskaplig litteratur på svenska bibliotek är att det helt enkelt finns för lite svensk/nordisk applicerbar forskning, och det som finns upplevs ofta som för teoretiskt. Som beskrivs ovan upplevs ibland även anglosaxisk forskning som svår att applicera pga för stora kulturella och/eller organisatoriska skillnader. Till detta kommer ett visst motstånd, och en ovana, vid att läsa komplexa texter på engelska.

EBLIP-arbetet på Karolinska Institutets Universitetsbibliotek började hösten 2004 då vi startade vår tidskriftsklubb, och som en följd av denna kom i kontakt med EBLIP-konceptet. Sedan dess har vi på olika sätt arbetat med att tillämpa evidensbaserade metoder i bibliotekets verksamhet (Haglund \& Herron, 2008). Sammanfattningsvis skulle man kunna säga att tankarna kring EBLIP och hur man kan tilllämpa arbetssättet hela tiden utvecklas, på KIB, men också hos de mer tongivande personerna (Booth, 2009). Utgångspunkten i resonemangen på KIB just nu handlar mycket om EBLIP som ett förhållningssätt i det dagliga arbetet, i motsats till den mer dogmatiska tillämpningen av EBLIP-processen. Vi ser också arbetet mer som en kollektiv process än en individuell övning, och resonerar kring användningen av uttrycket evidensinformerad eller forskningsinformerad istället för evidensbaserad, som en reaktion till ovanstående resonemang om bevis som något rationellt/svart eller vitt.

\section{Utbildningar inom Biblioteks- och informations- vetenskap}

I början av 1990-talet akademiserades utbildningen inom biblioteks- och informationsvetenskap i Sverige, inte utan protester från "fältet", där man ifrågasatte vad studenterna lärde sig på utbildningen, eftersom man "fick lära upp de nyutexaminerade på arbetsplatsen". Under de ca 15 år som har gått sedan utbildningen förändrades har ett stort antal bibliotekarier utbildats och fått anställning på svenska bibliotek. Rent teoretiskt borde det innebära ett större 
intresse och en större förståelse för att använda forskning/ett mer akademiskt arbetssätt i det praktiska arbetet. En förutsättning för att man ska kunna tillämpa detta är förstås att även biblioteksledningar ser nyttan av detta arbetssätt

I Sverige finns idag utbildningar inom Biblioteksoch informationsvetenskap (B\&I), med något olika inriktning, på följande lärosäten: Högskolan i Borås, Lunds universitet, Linnéuniversitetet Växjö/Kalmar, Uppsala universitet, samt Umeå universitet. Jag har varit i kontakt med företrädare ${ }^{1}$ för fyra av fem utbildningar för att undersöka om, och i så fall på vilket sätt, man undervisar om EBLIP inom biblioteksoch informationsvetenskap.

Med ett undantag svarar man att man inte i någon egentlig mening undervisar om EBLIP, men att man i vissa fall, eller i vissa kurser nämner, och problematiserar kring EBLIP-konceptet.

Undantaget är Uppsalautbildningen som uppger att man "tidigare har undervisat en grupp studenter i praxisnära forskning och EBLIP, men det är inget som förekommer regelbundet i undervisningen". Kerstin Rydbeck från Uppsala bedriver också själv ett projekt med titeln "Forskningscirkeln som metod för evidensbaserad biblioteks- och informationsvetenskaplig praktik" (http://www.abm.uu.se/index. php? sida $=5 \& \mathrm{id}=4$ [2010-11-29]), där en delrapport presenterades på konferensen EBLIP5 (se nedan).

Samtliga företrädare för B\&I-utbildningarna menar att en utbildning som vilar på akademisk grund inte skiljer sig i stort från resonemangen kring EBLIPprocessen, då det i båda fallen handlar om ett problematiserande arbetssätt, där man med utgångspunkt i forskningsprocessen definierar, undersöker och analyserar problemställningar. . Man resonerar också med studenterna om hur de kan dra nytta av och använda både forskningsresultat och ett forskande förhållningssätt när de så småningom blir yrkesverksamma bibliotekarier. Man poängterar också från flera håll det stora intresset från många av de verksamma lärarna och forskarna på B\&I-institutionerna för att belysa, diskutera och på så vis undervisa om frågor som har med kopplingen mellan forskningsoch utbildningssektorn och de yrkesverksamma på biblioteken att göra. Sammanfattningsvis konstaterar man att det i första hand handlar om ett förhållningssätt. $^{2}$

\section{Svensk biblioteksförening}

En viktig aktör inom biblioteksväsendet i Sverige är Svensk Biblioteksförening, som idag arbetar aktivt för ett närmande mellan forskning och praktik, bland annat genom att man uppmuntrar praktiknära forskning. I sitt utkast till Forskningspolicy, framtaget av Utvecklingsrådet för forskning och utveckling hösten $2010^{3}$ nämns inte begreppet $E B L I P$, men det grundläggande synsättet på en praktik baserad på forskning uttrycks på olika sätt i dokumentet:

Föreningen bör också på olika sätt ge professionen stöd $\mathrm{i}$ att hålla sig à jour med forskning på bred front och verka för att man på biblioteken ökar medvetenheten om forskningens betydelse för utvecklingen av den egna praktiken.

$[\ldots]$

Föreningen ska arbeta för att yrkesverksamma på bibliotek utvecklar ett forskande och reflekterande arbetssätt. Detta ska ske genom att [...]

- Peka på behovet av kompetensutvecklingsinsatser $t$ ex inom metoder för lärande och eget skrivande och publicering

- Lyfta fram goda exempel där biblioteksverksamhet har använt sig av forskning för att utveckla verksamheten

- Lyfta fram goda exempel på hur biblioteksverksamhet beforskas

Man konstaterar också att fler forskande praktiker behövs.

Som exempel på föreningens engagemang i frågan kan nämnas det bidrag man beviljat arrangörerna av konferensen EBLIP5 sommaren 2009, där också föreningens ordförande Inga Lundén höll ett uppskattat inledningsanförande. I föreningens tidskrift presenteras i varje nummer månadens uppsats. Föreningen delar också ut ett forskningsinitierande stöd.

\section{Kunskapen om EBLIP hos yrkesverksamma}

Våren 2007 skickade bibliotekariestudenten Eva Thorell (2010) ut ett mejl på diskussionslistan Biblist där hon efterlyste bibliotek "som använder sig av 'evidence-based librarianship' (EBL), även benämnd 'evidence-based practice' (EBP)". Hon fick tre(3) svar. 
Idag, snart fyra år senare, hade svarsfrekvensen kunnat se annorlunda ut. Genom tidskriftsartiklar, lobbyverksamhet, workshopar, medverkan i konferenser, och inte minst genom arrangerandet av 5th Evidence Based Library and Information Practice Conference (EBLIP5) (http://eblip5.kib.ki.se [2010-12-01]) sommaren 2009 har kunskapen om EBLIP ökat på svenska bibliotek.

Som ansvarsbibliotek för medicin har Karolinska Institutets Universitetsbibliotek (KIB) under en lång följd av år arrangerat kompetensutvecklingsaktiviteter för medicinska bibliotekarier, dels form av en årlig konferens, och dels som en vecka fylld av vidareutbildningskurser. I augusti 2006 bjöds en av EBLIPs förgrundsfigurer - Andrew Booth - in till den 9:e Medicinska bibliotekskonferensen. Andrew Booth höll en halvdagsworkshop på temat "Don't give up your day job" - using EBLIP in practice, samt en presentation med rubriken The Body (of Evidence) in the Library: enough evidence to find us guilty? under själva konferensen. Hösten 2008 följdes Andrew Booths workshop upp av en kurs under fortbildningsveckan, med titeln EBLIP - evidensbasera ditt arbete, med sammanlagt 19 deltagare.

Inför arrangerandet av EBLIP5 sommaren 2009 arrangerade KIB, tillsammans med Regionbibliotek Stockholm en kurs med rubriken Definitely, maybe eller Do the right thing. Målet med kursen var att introducera konceptet EBLIP samt att sprida kunskap om evidensbaserade metoder, och målgruppen var bibliotekarier från alla bibliotekstyper, i första hand från Stockholmsområdet ( Ögland, 2009).

Kursen hölls under våren 2009, och upprepades under våren 2010. Det sammanlagda deltagarantalet för båda kurserna var 78 personer från folk- och regionbibliotek (32), skolbibliotek (5), akademiska bibliotek (34), sjukhusbibliotek (5), samt en student och en deltagare med eget konsultföretag. Från KIB har totalt 11 personer deltagit i kursen och KIB utvärderar just nu den eventuella impakt detta har haft på verksamheten. Resultatet av utvärderingen kommer att presenteras på EBLIP6 (http://www.eblip6. salford.ac.uk/).

\section{EBLIP-konferenserna}

År 2001 tog en av förgrundsgestalterna inom EBLIP - Andrew Booth - initiativet till att ordna en konfe- rens på temat EBLIP. Denna konferens kom att bli den första av hittills fem konferenser, den sjätte kommer att äga rum i Manchester, UK sommaren 2011. Konferenserna har i tur och ordning ägt rum $\mathrm{i}$

- Sheffield, UK (EBLIP1) ( http://andrewbooth. pbworks.com/w/page/27205078/EBL2001 [201012-01])

- Edmonton, Kanada (EBLIP2) http://web.archive. org/web/20060914000532/http:/www.asebl.ualberta.ca/ [2010-12-01]

- Brisbane, Australien (EBLIP3) (http://conferences.alia.org.au/ebl2005/ [2010-12-01])

- Chapel Hill-Durham, NC, USA (EBLIP4) (http:// www.eblip4.unc.edu/ [2010-12-01])

- Stockholm, Sverige (EBLIP5) (http://eblip5.kib. ki.se [2010-12-01])

De fyra första konferenserna lockade sammanlagt endast två svenska deltagare (Edmonton \& Chapel Hill-Durham), och ett svenskt paper har presenterats (Chapel Hill-Durham).

Den femte konferensen arrangerades av Karolinska Institutets Universitetsbibliotek, i samarbete med flera bibliotek i Stockholmstrakten. I Local Organizing Committee ingick fyra personer från folkbibliotek, en från Kungliga Biblioteket, en från sjukhusbibliotek, och fyra från akademiska bibliotek (varav 3 från KIB). Ett av konferensens mål var att sprida kunskap om EBLIP i Sverige (och Europa) samt att locka deltagare från alla bibliotekstyper.

Totalt deltog 163 personer från 18 olika länder, varav 68 från Sverige. Av dessa var 41 från universitetsbibliotek, tio från sjukhusbibliotek, sju från folkbibliotek, fem från Kungliga Biblioteket, två från regionbibliotek, två från förening/myndighet, och en från ett företagsbibliotek.

I de fem workshoparna före och efter EBLIP5 deltog totalt 36 personer från Sverige.

De svenska deltagarna var också aktiva under konferensen, av de fem inbjudna huvudtalarna var tre svenska. Totalt skickades det in sex svenska abstracts till konferensens Call for papers, varav 4 presenterades muntligt och två som posters. En av de svenska postrarna vann konferensens utmärkelse för bästa poster. 
För den kommande konferensen (EBLIP6) sommaren 2011 har tre svenskar hittills registrerat sitt intresse för att delta, och enligt förhandsuppgifter från arrangörerna ${ }^{4}$ har ungefär lika många abstrakts skickats in från Sverige som till EBLIP5.

\section{Framtiden för EBLIP i Sverige}

I vilken mån EBLIP tillämpas på de svenska biblioteken är omöjligt att säga. Sammantaget har över 200 personer deltagit i kompetenshöjande aktiviteter på temat EBLIP de senaste 4-5 åren. Detta kombinerat med akademiseringen av B\&I-utbildningarna kommer troligen på sikt att påverka arbetssättet på svenska bibliotek mot en ökad medvetenhet om behovet av att fatta välgrundade beslut, på basis av bland annat forskningsresultat. Om man sedan väljer att sätta etiketten EBLIP på sitt arbete är kanske inte så viktigt, det viktiga är det grundläggande förhållningssättet och att kunna integrera detta förhållningssätt i den dagliga verksamheten.

\section{Noter}

1. Ola Pilerot, Borås; Angela Zetterlund, Växjö; Kerstin Rydbeck, Uppsala, Rickard Darnell, Umeå. Saknas gör företrädare för BIVIL i Lund, som jag inte kunnat nå för kommentar.

2. Personlig kommunikation med Ola Pilerot, Angela Zetterlund $\mathrm{m}$ fl, november 2010.

3. Jag har fått tillgång till utkastet till Forskningpolicy genom personlig kommunikation med Lotta Åstrand, medlem i Utvecklingsrådet för forskning och utveckling. Dokumentet ännu ej godkänt av Biblioteksföreningens styrelse (201012-02).

4. Personlig kommunikation med Dr Alison Brettle, Centre for Nursing and Midwifery Research, University of Salford, UK.

\section{Referenser}

Booth, A \& Brice, A (eds.)(2004). Evidence- based practice for information professionals : a handbook. London : Facet.

Booth, A (2009). EBLIP five-point-zero : towards a collaborative model of evidence-based practice. $\mathrm{He}$ alth Information \& Libraries Journal 2009, 26(4), 341-344.

Haglund, L \& Herron, D (2008). Evidensbaserat biblioteksarbete som metod att stimulera kompetensutveckling. Mötesplats för framtiden, 15-16 oktober 2008 i Borås. [http://bada.hb.se/bitstream/2320/4059/1/HaglundHerron.pdf] 2010-12-01.

Thorell, E (2010). Evidensbaserat arbete på bibliotek: erfarenheter av användningen av EBLIP. Magisteruppsats i Biblioteks- och informationsvetenskap/Bibliotekshögskolan, 2010:30.

Pilerot, O (2007). Från forskning till praktik - om att använda resultat från forskning om informationssökning i undervisning i informationssökning. Paper presenterat vid konferensen Mötesplats inför framtiden, 10-11 oktober 2007 i Borås. [http://bada.hb.se/ bitstream/2320/2577/2/Pilerot_2007.pdf]

2010-12-01.

Ögland, M \& Åstrand, L \& Herron, D (2009). Definitely, maybe or Do the right thing! Bridging the gap between research and public libraries - developing professional reflective practitioners; looking back, around and forward, in order to be prepared for the future. Presentation vid the 5th Evidence Based Library and Information Practice Conference, 29th June - 3rd July 2009, Stockholm, Sweden. [http:// blogs.kib.ki.se/eblip5/presentations/MOglandpresentation.pdf och http://blogs.kib.ki.se/eblip5/abstracts/ ogland.pdf] 2010-12-08. 